\title{
Sap flow scaling and crop coefficient of dry-farmed olive orchards converted to irrigation
}

Francisco L. Santos, Pedro C. Valverde, João L. Reis, Alice F. Ramos, Nádia L. Castanheira

Instituto de Ciências Agrárias Mediterrânicas (ICAM)

Universidade de Évora

Apartado 94, 7002-554

Évora, Portugal

Keywords: scaling sap flow, cluster transpiration, stand olive tree transpiration, olive tree crop coefficient, water stress coefficient, olive tree irrigation needs

\begin{abstract}
Tree water uptake is often estimated based in a crop coefficient $k_{c}$, a ratio of the tree water uptake and a reference evapotranspiration, ETO. The concept behind estimating tree crop coefficient implies that data should be representative of the population of trees analyzed. Ideally it would require the monitoring of a large number of trees in each treatment population. This paper reports on a scaling method to establish stand-level transpiration estimates and crop coefficients from individual sampled tree sap flow measurements. The scaling technique was implemented for individual tree sap flow measurements on the following irrigation treatments: A, fully-irrigated; B, irrigated to provide for approximately $60 \%$ of crop evapotranspiration; $C$, irrigated to provide for $100 \%$ of crop evapotranspiration during three critical phase periods: before-flowering, at beginning of pit-hardening and before crop-harvesting, and dry-farming treatment $D$. Results show that stand transpiration $T$ depart from individual tree transpiration values. They consequently were used to establish crop, $k_{c}$ and water stress, $k_{s}$ coefficients to account for the cluster's characteristics and degree of tree's water uptake. Using the individual tree transpiration rates would be less appropriate.
\end{abstract}

\section{INTRODUCTION}

Crop coefficient methods are based on an engineering approach that is widely recognized in irrigation agriculture. The core of these methods is the determination of a crop transpiration coefficient, $k s$ which represents the evapotranspiration of a given crop, $T$ as a proportion of the evapotranspiration, ETO of an ideal (reference) crop grown under no limitation of water and nutrients (Allen et al. 1998). ETO is derived from meteorological data providing a generally accepted measure of the local atmospheric water demand. The crop coefficient, once established for an ideal water supply and validated for local conditions, can provide for an easy method to determine tree irrigation needs. The objective of this work was to use individual tree sap flow measurements to derive stand transpiration by a scaling up technique, and estimate crop and water stress coefficients to support the irrigation management of olive trees of cv. Cordovil grown in Southern Portugal. 


\section{MATERIALS AND METHODS}

An 80-plus year old dry-farmed olive orchard planted on a 12 x $12 \mathrm{~m}$ spacing layout was used in the experiment. Sap flow rates and transpiration of a representative tree in each irrigation treatment was obtained from implanted heat pulse probes at three different positions around the trunk and by using the compensation heat pulse technique (CHP) described in Green \& Clothier (1988) and Green et al. (2003). ET0 estimates for the site where derived from the recommended by FAO Penman-Monteith combination equation (Allen et al. 1998).

\section{Sap flow scaling and orchard transpiration}

Stand transpiration $T$ for each irrigation treatment was calculated based on individual tree sap flow, total sapwood area, SWA and total canopy area of the treatment cluster of trees. The total canopy area of the cluster of trees in each treatment was estimated from average values taken from a sample of eleven randomly chosen trees multiplied by their total number. The sap flow rates were recalculated to determine the sap flow rate of the tree cluster for each treatment. For the purpose of scaling, the sapwood section of the trunk quantified as an area, i.e. sapwood area, SWA was obtained in each individual tree by considering the average sapwood depth as the section visually identified with a light colouration from a set of three core samples extracted with a $150 \mathrm{~mm}$ Suunto increment core borer. The total sapwood area of all trees in the stand was determined considering a set of nine randomly chosen trees of different trunk diameters where a linear relationship was observed between trunk diameter and the sapwood area, thus a linear equation was established defining total sapwood area, SWA in $\mathrm{m}^{2}$ as a function of the trunk diameter, $t_{d i}$ in $\mathrm{m}$

$$
S W A=0.1702 t_{d i}-0.0076
$$

Each sampled tree equipped with sap flow probes had its sapwood radial profile equipped with three probes with four thermocouple sensors each placed at 5, 12, 21 and $35 \mathrm{~mm}$ depth. Considering the average of the three probes in each tree, the total sap flow Js is computed as

$$
J_{S}=V_{1} S W A_{1}+V_{2} S W A_{2}+V_{3} S W A_{3}+V_{4} S W A_{4}
$$

where $J s$ is the total sap flow rate in $\mathrm{m}^{3} / \mathrm{h}$; $V_{\mathrm{n}}$ is the average corrected sap flow velocity at thermocouple sensor $n$ in $\mathrm{m} / \mathrm{h}$; $S W A_{n}$ is the sapwood area corresponding to the thermocouple sensor $n$ in $\mathrm{m}^{2}$ and $n$ is the number subscripts at the four thermocouple sensor positions. The total sap flow rate of the stand $J S_{\text {stand }}$ in $\mathrm{m}^{3} / \mathrm{h}$ in each treatment is now divided by the total sapwood area of the measured tree (SWA) and multiplied by the total sapwood area of the tree stand, $S W A_{\text {stand }}$

$$
J_{S_{\text {stand }}}=(J S / S W A) S W A_{\text {stand }}
$$

To obtain the transpiration $T$ in $\mathrm{L} / \mathrm{h}$ of the hypothetical tree representing the average of the cluster in each treatment, the total sap flow of the stand $J S_{\text {stand }}$ in $\mathrm{m}^{3} / \mathrm{h}$ is multiplied by 1000 to convert it to $\mathrm{L} / \mathrm{h}$, then divided by the canopy area $A_{c m}$ in $\mathrm{m}^{2}$ of the tree where sap flow was measured and multiplied by the average canopy area of the trees in the cluster $A_{c c}$ in $\mathrm{m}^{2}$ 


$$
T=\left(1000 J s_{\text {stand }}\right)\left(A_{c s} / A_{c m}\right)
$$

The daily transpiration $T$ in L/day was then determined by integrating in time the 30 minute-interval measurements provided by the sap flow probes, consisting in a total of 24 measurements per day. Only day light data was used in the calculations, to be sure that radiation was not a limiting factor.

$$
T=\sum_{n=1}^{47}\left(0.5\left(\frac{T_{n}+T_{n+1}}{2}\right)\right)
$$

The daily transpiration $T$ in L/day was converted to ground-area based transpiration $T$ in $\mathrm{mm}$ /day dividing $\mathrm{T}$ by the total canopy area of the olive tree population $A_{c t}$ in $\mathrm{m}^{2}$

$$
T(\mathrm{~mm} / \text { day })=T(\mathrm{~L} / \text { day }) / A_{c t}
$$

\section{Crop and water stress coefficient}

Reference evapotranspiration, ETO is strictly a measure of the capacity of the atmosphere to influence water loss from an ideally vegetated surface that is subject to no resource limitations (Allen et al., 1998). The goal of establishing ETO is to have a reference value of evapotranspiration for a given location against which the evapotranspiration of any crop can be related. ETO is related to the evapotranspiration of a crop as follows:

$$
k c=E T_{c} / E T 0
$$

where $k c$ is crop transpiration coefficient, $E T_{c}$ is crop evapotranspiration, and ETO is reference evapotranspiration. Both $E T 0$ and $E T_{c}$ are obtained under optimum conditions. Therefore, $k_{\mathrm{c}}$ parameters are dictated by how different a crop responds to the weather in relation to the reference crop. When $k_{c}$ for a given crop is known, it is used together with $E T 0$ to calculate the irrigation requirements or evapotranspiration $\left(E T_{c}\right)$ of the crop. Due to negligible soil evaporation in the drip irrigated treatments, crop coefficient $k_{c}$ is defined in this work as:

$$
k_{c}=T / E T O
$$

Under the deficit irrigation water treatments, adjustments for low soil water available involved the determination of $k_{s}$, a water stress coefficient that was used to modify $k_{c}$ and to calculate and adjust $T$ for water stress condition (Allen et al, 1998) as

$$
T=k_{c} k_{s} E T 0
$$

The value of $k_{s}$ ranges between zero and one. When there is adequate soil water available, no stress is imposed in plants and $k_{s}$ equal 1 . Stand-level transpiration estimates from scaling sampled individual trees was used to calculate $T$ values for each treatment, A, B, C and dry-farming. 


\section{RESULTS AND DISCUSSION}

Stand transpiration rates were higher for treatment B and distinct from treatment A that received approximately $40 \%$ more water throughout the growing season. A marked decline in sap flow values for treatment $C$ was observed during the peak of summer drought following the irrigation events in July (Table 1). Table 2 gives account on the accumulative stand transpiration values for each treatment, with a total of $704 \mathrm{~mm}$ for treatment A, $745 \mathrm{~mm}$ for treatment B, $638 \mathrm{~mm}$ for treatment C and $404 \mathrm{~mm}$ for treatment D. Individual tree transpiration reported in Table 1 were $657 \mathrm{~mm}$ for treatment A, 599 $\mathrm{mm}$ for treatment B, $726 \mathrm{~mm}$ for treatment C and $373 \mathrm{~mm}$ for treatment $\mathrm{D}$.

Table 3 shows the average T/ETO throughout the irrigation season calculated for each treatment A, B, C and dry-farming, to account for each stand characteristics and water applied. Larger T/ETO values occur in March and April when the moisture stored in the soil from winter rains and first irrigation events (Fig 1. and Table 1) is still high. As drought from summer months occurs, olive trees slow down their physiological mechanisms to conserve water and reduce their T/ETO ratio, regardless of water applied. Because of their secular adaptation to water limitations, olive trees typically display high resistance to transpiration. Accordingly, despite the large amount of water applied to treatment A, T/ETO ratio declined regardless throughout summer, to values as low as 0.6. Also treatment $\mathrm{B}$ that received the amount of water necessary to compensate for transpiration showed a similar decline in T/ETO values during the same months, but with slightly higher values than treatment A.

Table 4 presents the monthly estimates of $k_{s}$ water stress coefficient for the water deficit treatments $\mathrm{C}$ and $\mathrm{D}$, obtained as the ratio of T/ETO to corresponding T/ETO values of the well-irrigated treatment B. Monthly estimates of $k_{s}$ water stress coefficient confirm the steadily decline in transpiration rates of treatment $C$ from its June value of $96 \%$ of treatment B to $39 \%$ by September. Irrigating treatment $\mathrm{C}$ helped sustained soil water stress to values close to $77 \%$ of treatment B in the month of June and to 52\% in August. Nevertheless, trees satisfied most of their atmospheric evaporative demands by extracting water from the larger volume of soil in the $12 \times 12 \mathrm{~m}$ tree spacing outside of the drip irrigation emitter wet bulb. The dry-farmed treatment that beneficiated from the same amount of rainfall but was not irrigated showed much sharper decline in stress coefficient, with $k s$ values of 0.66 in June, 0.44 in August and 0.49 in September.

\section{CONCLUSIONS}

Scaled up orchard transpiration based on individual tree transpiration was used to define orchard crop and water stress coefficients. They reflect the structural characteristics of the tree cluster in each treatment and the irrigation regime imposed to treatments. Estimated crop coefficients show that as summer drought occur, olive trees slow down their physiological mechanisms to conserve water and regardless of the water applied they reduce T/ETO ratios. During this resting phase applying water in excess of needed to sustain tree transpiration, as for treatment $A$, is inefficient for vegetative growth and carried losses from soil evaporation. Transpiration rates closely matching crop evapotranspiration obtained from soil water balance estimates (data not reported) recommend taking treatment $\mathrm{B}$ derived crop coefficients as more appropriate for scheduling irrigation of cv. Cordovil orchards in Southern Portugal. Applying irrigation to treatment C helped sustain orchard transpiration to $67 \%$ of treatment B in July and to $55 \%$ until mid August, fact also supported by the monthly estimates of $k s$ soil water stress 
coefficient. Nevertheless, with treatment C irrigation accounting for $11 \%$ of the $638 \mathrm{~mm}$ total transpiration and the surplus extracted by roots in the large volume of soil inbetween tree spacing, using the derived $k_{c}$ and $k_{s}$ to schedule irrigation of olive trees seems appropriate only in wet years of well distributed late summer rainfall. In general, and more so in years of no summer and early autumn rains, the irrigation regime of treatment B seems more appropriate for scheduling irrigation of olive trees in Southern Portugal.

\section{ACKNOWLEGMENTS}

This work was made possible by partial funding from the Integrated Development of the Alqueva Área Program (PEDIZA II) and by the Agricultural and Rural Development Operational Program AGRO (Medida 8, Acção 8.1, projecto AGRO 728). The leading author acknowledges the sabbatical leave scholarship provided by the Fundação para a Ciência e a Tecnologia (FCT).

\section{Literatura cited}

Allen, R.; Pereira, L.S.; Raes, D. and Smith, M. 1998. Crop evapotranspiration, Guidelines for computing crop water requirements. FAO Irrigation and Drainage Paper No. 56, Rome.

Green S.R. and Clothier B.E. 1988. Water use of kiwifruit vines and apple trees by the heat-pulse technique. Journal of Experimental Botany, 39, 115-123.

Green S.R., Clothier B.E. and Jardine B. 2003. Theory and practical application of heatpulse to measure sap flow. Agronomy Journal, 95, 1371-1379. 


\section{$\underline{\text { Tables }}$}

Table 1. Accumulated values of rainfall, reference evapotranspiration ET0, irrigation and transpiration from individual tree sap flow measurements for each treatment, $\mathrm{mm}$.

\begin{tabular}{|c|c|c|c|c|c|c|c|c|c|c|}
\hline \multirow[t]{2}{*}{ Start } & \multirow[t]{2}{*}{ End } & \multirow[t]{2}{*}{ ET0,mm } & \multirow{2}{*}{$\begin{array}{l}\text { Rainfall, } \\
\text { mm }\end{array}$} & \multicolumn{3}{|c|}{ Irrigation ,mm } & \multicolumn{4}{|c|}{ Transpiration from sap flow, mm } \\
\hline & & & & A & B & $\mathrm{C}$ & A & B & $\mathrm{C}$ & Dry-farming \\
\hline 18-Mar & 31-Mar & 33.5 & 44.4 & 4.7 & 2.4 & 3.2 & 22.7 & 21.9 & 34.7 & 19.0 \\
\hline 01-Apr & 15-Apr & 45.0 & 19.9 & 4.7 & 2.4 & 3.2 & 31.9 & 33.0 & 49.2 & 22.6 \\
\hline 16-Apr & 28-Apr & 41.4 & 9.8 & 15.8 & 8.1 & 0.0 & 31.3 & 33.5 & 46.6 & 22.8 \\
\hline 29-Apr & 12-Мау & 58.6 & 0.0 & 33.2 & 16.5 & 22.6 & 42.7 & 39.5 & 63.5 & 26.8 \\
\hline 13-Мау & 26-Мау & 73.0 & 0.5 & 42.7 & 21.8 & 6.5 & 41.5 & 35.0 & 63.0 & 22.8 \\
\hline 27-May & 09-Jun & 79.0 & 0.0 & 47.4 & 24.2 & 0.0 & 43.8 & 39.0 & 60.5 & 17.6 \\
\hline 10-Jun & 24-Jun & 79.0 & 49.2 & 39.5 & 20.1 & 0.0 & 46.7 & 43.8 & 59.5 & 10.6 \\
\hline 25-Jun & 06-Jul & 69.8 & 0.0 & 44.2 & 22.6 & 22.6 & 38.9 & 37.5 & 45.5 & 34.0 \\
\hline 07-Jul & 19-Jul & 82.3 & 11.5 & 79.0 & 40.3 & 10.8 & 46.5 & 47.1 & 55.7 & 28.1 \\
\hline 20-Jul & 03-Aug & 97.3 & 0.0 & 113.8 & 58.0 & 0.0 & 56.6 & 55.6 & 52.2 & 30.4 \\
\hline 04-Aug & 17-Aug & 84.6 & 13.1 & 110.6 & 56.4 & 0.0 & 53.6 & 52.1 & 40.7 & 27.3 \\
\hline 18-Aug & 09-Sep & 124.7 & 2.3 & 178.6 & 91.0 & 0.0 & 84.0 & 88.6 & 59.0 & 44.0 \\
\hline 10-Sep & 25-Sep & 61.7 & 22.2 & 75.8 & 38.7 & 0.0 & 55.2 & 72.7 & 48.3 & 28.1 \\
\hline 26-Sep & $20-$-Oct & 72.2 & 67.5 & 90.1 & 45.9 & 0.0 & 61.7 & N/A & 47.1 & 38.5 \\
\hline
\end{tabular}

Table 2. Stand transpiration $T$ estimated, mm from sap flow measurements in individual trees. Results estimate transpiration of hypothetical olive tree for each treatment representative of the average structural characteristics of the cluster.

\begin{tabular}{|c|c|c|c|c|c|}
\hline \multirow[t]{2}{*}{ Start } & \multirow[t]{2}{*}{ End } & \multicolumn{4}{|c|}{ Treatment } \\
\hline & & A & B & C & $\begin{array}{c}\text { Dry- } \\
\text { farming }\end{array}$ \\
\hline 18-Mar & 31-Mar & 24.0 & 28.6 & 31.4 & 20.6 \\
\hline 1-Apr & 15-Apr & 33.6 & 43.2 & 44.6 & 24.4 \\
\hline 16-Apr & 28-Apr & 32.9 & 43.8 & 42.3 & 24.4 \\
\hline 29-Apr & 12-May & 44.8 & 51.5 & 57.7 & 28.5 \\
\hline 13-May & 26-May & 43.6 & 45.5 & 57.3 & 24.3 \\
\hline 27-May & 9-Jun & 46.0 & 50.8 & 55.2 & 22.1 \\
\hline 10-Jun & 24-Jun & 48.9 & 57.1 & 54.3 & 12.3 \\
\hline 25-Jun & 6-Jul & 40.8 & 48.8 & 41.6 & 40.4 \\
\hline 7-Jul & 19-Jul & 48.7 & 61.1 & 50.7 & 30.1 \\
\hline 20-Jul & 3-Aug & 55.1 & 67.2 & 44.9 & 30.3 \\
\hline 4-Aug & 17-Aug & 56.1 & 67.7 & 37.3 & 29.0 \\
\hline 18-Aug & 9-Sep & 87.9 & 115.6 & 54.2 & 46.8 \\
\hline 10-Sep & 25-Sep & 56.5 & 64.3 & 23.2 & 29.7 \\
\hline 26-Sep & $20-$ Oct & 84.8 & N/A & 43.4 & 40.6 \\
\hline
\end{tabular}


Table 3. Monthly $k_{c}$, estimated as T/ET0, the ratio between scaled transpiration for each treatment, mm/day and Penman-Monteith ET0, mm/day.

\begin{tabular}{ccccc}
\hline & A & B & C & $\begin{array}{c}\text { Dry - } \\
\text { farming }\end{array}$ \\
\hline Mar & 0.75 & 0.92 & 0.88 & 0.65 \\
Apr & 0.80 & 1.02 & 1.03 & 0.59 \\
May & 0.69 & 0.73 & 0.88 & 0.40 \\
Jun & 0.61 & 0.70 & 0.67 & 0.46 \\
Jul & 0.60 & 0.74 & 0.57 & 0.39 \\
Aug & 0.67 & 0.84 & 0.44 & 0.37 \\
Sep & 0.91 & 1.01 & 0.39 & 0.49 \\
Oct & N/A & N/A & 1.04 & 0.70 \\
\hline
\end{tabular}

Table 4. Monthly water stress coefficient $k_{s}$ for treatment $\mathrm{C}$ and D obtained as the ratio of their T/ETO estimates (table 3) to corresponding T/ETO values for the well-watered treatment B.

\begin{tabular}{ccc}
\hline & C & $\begin{array}{c}\text { Dry - } \\
\text { farming }\end{array}$ \\
\hline Mar & 0.96 & 0.70 \\
Apr & 1.00 & 0.59 \\
May & 1.20 & 0.55 \\
Jun & 0.96 & 0.66 \\
Jul & 0.77 & 0.53 \\
Aug & 0.52 & 0.44 \\
Sep & 0.39 & 0.49 \\
Oct & 1.00 & 0.70 \\
\hline
\end{tabular}




\section{Figures}

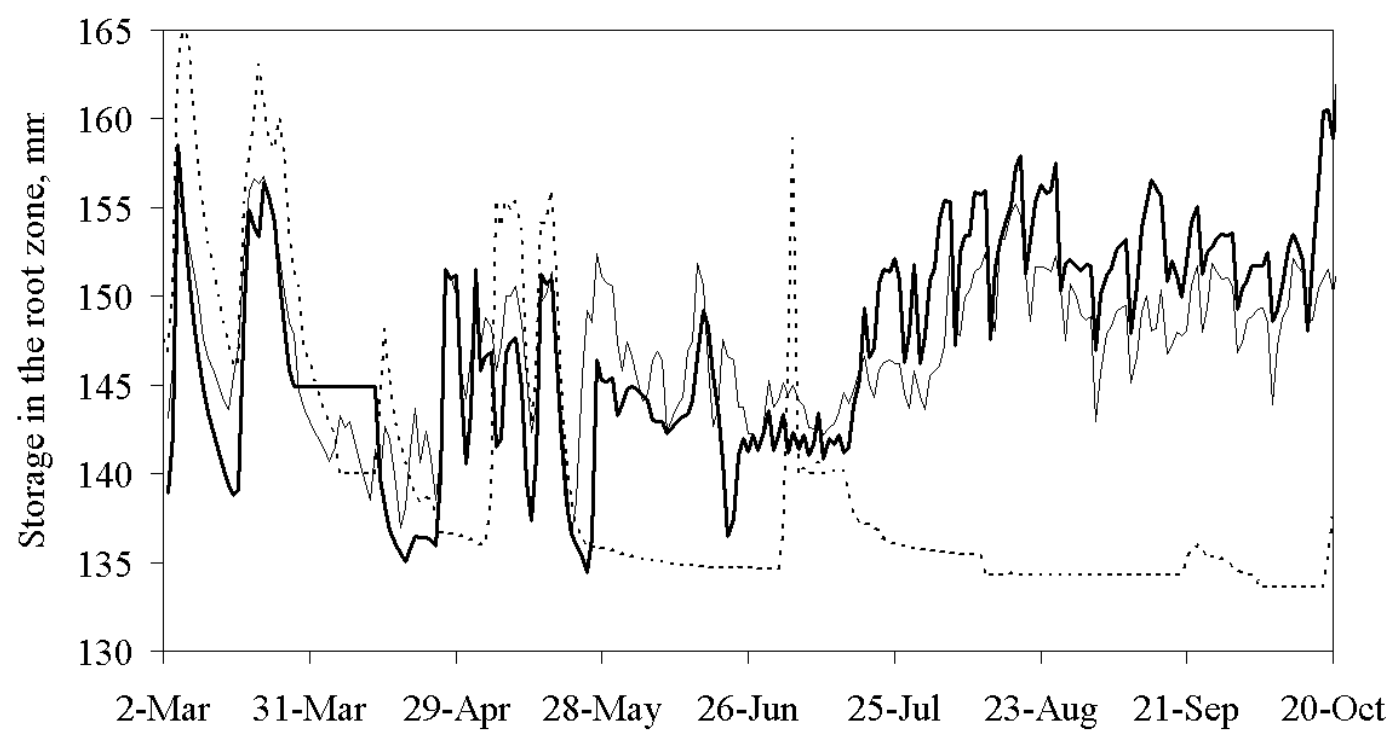

Figure 1. Water storage in the root zone computed with watermark sensors for each treatment: treatment $\mathrm{A}$, —; treatment $\mathrm{B}$, —;treatment $\mathrm{C}$, - - - . 